\title{
Sepiolite Enhances Biomineralization Activity of The Cementoblasts
}

\author{
Sema S Hakki ${ }^{1,2 *}$, Serife Buket Bozkurt ${ }^{2,3}$, Esma Yenel ${ }^{4}$ and Mahmut Kus ${ }^{5}$ \\ ${ }^{1}$ Faculty of Dentistry, Department of Periodontology, Selcuk University, Turkey \\ ${ }^{2}$ Research Center of Dental Faculty, Selcuk University, Turkey \\ ${ }^{3}$ Faculty of Dentistry, Research Lab, Hacettepe University, Turkey
}

${ }^{4} J u n i o r$ Technical Science College, Nuclear Energy and Radiation Safety Program, Konya Technical University, Turkey

${ }^{5}$ Department of Chemical Engineering, Konya Technical University, Turkey

*Corresponding author: Sema S Hakki, Faculty of Dentistry, Selcuk University, Konya, 42079, Turkey.

To Cite This Article: Sema S Hakki, Sepiolite Enhances Biomineralization Activity of The Cementoblasts. 2020 - 9(6). AJBSR.MS.ID.001447. DOI: 10.34297/AJBSR.2020.09.001447.

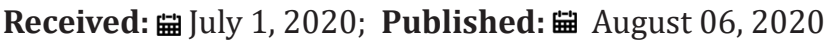

\begin{abstract}
Aim: The inductive potentials of graft materials are important for regenerative therapies. Thus, this study was conducted using cementoblasts (OCCM-30) tooth root lining cells to determine whether sepiolite affected proliferation, mRNA expressions of genes associated with cementum/bone and biomineralization.

Materials and Methods: The media containing released components of sepiolite (100 mg/ml ratio; waited $72 \mathrm{hrs} \mathrm{in} 5 \% \mathrm{FBS}$ containing media) were used for cementoblast's treatments. Proliferation of the cells was evaluated using a real-time cell analyzer (RTCA) for 170 hrs. After total RNA isolation on days 3 and 6, cDNA synthesis was performed. Bone sialoprotein (BSP), osteocalcin (OCN), collagen type I (COL-I), runt-related transcription factor 2 (Runx2), and alkaline phosphatase (ALP) transcripts were examined employing quantitative RT-PCR. Biomineralization of the cementoblasts was evaluated on day 8 via von Kossa staining.

Results: Sepiolite decreased proliferation of the cementoblasts when compared to untreated control group. While there was no change for BSP mRNA expression for both time points, sepiolite up-regulated OCN, Runx2, COL-I and ALP mRNA expressions ( $p<0.01$ ) on days 3 and 6 when compared to control. Sepiolite stimulated mineralized nodule formation of the cementoblasts when compared to mineralization media group (positive control).

Conclusion: The findings of this study demonstrated that sepiolite enhances the functions of the cementoblasts involving new cementum formation which is critical for periodontal regeneration. Results suggested that sepiolite has potential as a graft material in dentistry and medicine.
\end{abstract}

Keywords: Sepiolite, Cementoblasts, Mineralized Tissue, Periodontal Regeneration, Cementum

\section{Introduction}

Huge numbers of biomaterials with/without growth and differentiation factors have been investigated in dentistry and orthopedics aiming regenerative procedures. Platelet derived growth factor (PDFG), basic fibroblast growth factor (bFGF) and/or bone morphogenetic proteins (BMPs), enamel matrix proteins containing graft materials have been widely assessed [1-8]. However, recombinant technologies and production cost of these osteoinductive materials in general are expensive. Researchers focus to find safe, cheap, easily accessible, and bioactive materials to replace with others in regenerative medicine [5-8]. 
To date several alternative biografts for regenerative purpose have been synthesized. Trace elements like; boron, selenium etc. were incorporated to the materials to induce mineralized tissue formation [9-11]. Gelatin, cuttlefish backbone, meerschaum sepiolite, hydroxyapatite and chitosan based scaffolds as graft substitutes were provided acceptable mechanical structure and cell viability rates $[12,13]$. Sepiolite known as meerschaum is nanoclay which has complex magnesium silicate. Sepiolite might have potentials for regenerative therapies due to extremely active surface area $(\sim 300$ $\mathrm{m}^{2} /$ gr) $[14,15]$, safety and easily accessibility in nature.

The aim of regenerative therapies is to improve the migration, proliferation, and differentiation progenitor and/or stem cells to the differentiated cells synthesizing extracellular matrix components appropriate for targeted tissue/organ. Cementum is specialized calcified substance covering the root of a tooth and the part of the periodontium that attaches the teeth to the alveolar bone by anchoring the periodontal ligament [16]. The regeneration of periodontium requires key components including cells, signals, scaffolds, and an appropriate niche providing wound healing without scar formation. Osteoblasts, cementoblasts, progenitor cells/mesenchymal stem cells for new alveolar bone, cementum and periodontal ligament tissue formation respectively are the criteria of the periodontal regeneration [17]. Due to limited regenerative capacity and avascular structure of cementum; the induction of tooth root lining cells is very critical $[16,17]$. The aim of this study is to assess the effects of sepiolite on the proliferation, mRNA expressions of the mineralized tissue associated genes; including Bone sialoprotein (BSP), osteocalcin (OCN), collagen type I (COL-I), runt-related transcription factor 2 (Runx2), and alkaline phosphatase (ALP) and biomineralization of the cementoblasts.

\section{Materials and Methods}

\section{Culture of Cementoblasts}

An immortalized mouse cementoblast cell line OCCM-30 (kindly provided by Dr. Martha J. Somerman) was cultured in Dulbecco's modified Eagle's medium (DMEM; GIBCO; Grand Island, NY, USA), $10 \%$ fetal bovine serum (FBS; GIBCO), L glutamine $(600 \mathrm{mg} / \mathrm{ml}$; GIBCO;), penicillin (100 U/ml; GIBCO), and streptomycin (125 mg/ $\mathrm{ml}$; GIBCO) in a humidified atmosphere of $5 \% \mathrm{CO}_{2}$.

\section{Preparation of Graft Material's Solutions}

Sepiolite at $100 \mathrm{mg} / \mathrm{mL}$ concentrations were incubated in $5 \%$ DMEM medium for 72 hours at $37^{\circ} \mathrm{C}$ according to ISO 1099312:2007 and 7405:2008. After incubation period, media obtained containing bioactive components released from graft materials and this extract medium was filtered using $0.22 \mu \mathrm{m}$ pore size filter for cell culture experiments.

\section{Cell Proliferation Assay}

The effect of sepiolite on the cementoblast's proliferation, real time cell analyzer (RTCA-SP; xCELLigence) was used. $200 \mu \mathrm{L}$ cell suspensions, $\left(5 \times 10^{3}\right.$ cell/well) was seeded to the wells of a 96-well view E-plate for 24 hours. The following day, $200 \mu \mathrm{L}$ DMEM containing released components of sepiolite was applied to each well and the proliferative curve of the cementoblasts was determined every 15 minutes for 170 hours.

\section{RNA Isolation and Real-Time Polymerase Chain Reaction}

Cells were added in $60 \mathrm{~mm}$ cell culture dishes $25 \times 10^{3}$ cells/ $\mathrm{cm}^{2}$ for $24 \mathrm{~h}$. Then, OCCM-30 cells were treated with the DMEM with sepiolite and total RNA was isolated using a monophasic solution of phenol and guanidine isothiocyanate on day 3 and day 6 . The RNA concentrations were measured at nanodrop and stored at $-80^{\circ} \mathrm{C}$ until complementary DNA (cDNA) synthesis. First-strand cDNA was transcribed from $1 \mu \mathrm{g}$ of RNA by cDNA synthesis kit in accordance with the manufacturer's protocol. Quantitative real-time polymerase chain reaction was also performed with the Strategene MX3000P with SYBR Green QPCR Master Mix in triplicate. The amplification profile included 95/600; 95/15; 60/60; 72/30 (temperature in ${ }^{\circ} \mathrm{C} /$ time in seconds), and 35 to 40 cycles. The primers for mouse BSP, OCN, COL-I, RunX2, ALP and GAPDH were used in PCR reactions (Table 1).

Table 1: Synthetic oligonucleotide primer sequences for RT-PCR. All sequences are from mouse and listed 5' - 3'. GAPDH was used as housekeeping gene for normalization.

\begin{tabular}{|c|c|c|}
\hline Primer & Forward & Reverse \\
\hline COL- I & GCAACATTGGATTCCCTGGACC & GTTCACCCTTTTCTCCCTTGCC \\
\hline BSP & GAGACGGCGATAGTTCC & AGTGCCGCTAACTCAA \\
\hline OCN & TGAACAGACTCCGGCG & GTACACTTAGATGCGTTTG \\
\hline Runx2 & CTTCATTCGCCTCACAAAC & CCTCTGGTGGCATCTCGTTATC \\
\hline ALP & ATTGCCCTGAAACTCCAAAACC & TCCACCACCCTGTTGCTGTA \\
\hline GAPDH & ACCACAGTCCATGCCATCAC \\
\hline
\end{tabular}

\section{Mineralization Experiment}

Von Kossa staining was performed to observe mineralized nodules. Cementoblasts was added $5 \times 10^{4}$ cells $/ \mathrm{cm}^{2} 24$-well plates in
DMEM containing $10 \% \mathrm{FBS}$ and was incubated at $37^{\circ} \mathrm{C} 5 \% \mathrm{CO}_{2}$ for 24 hours. Following this incubation, cells were treated with 5\% FBS DMEM+ $50 \mu \mathrm{g} / \mathrm{ml}$ ascorbic acid and $10 \mathrm{mM} \boldsymbol{\beta}$-glycerophosphate 
(Mineralization Media; MM; positive control) and 5\% FBS DMEM containing released components of sepiolite $+50 \mu \mathrm{g} / \mathrm{ml}$ ascorbic acid and $10 \mathrm{mM} \boldsymbol{\beta}$-glycerophosphate groups). On day 8 , cmentoblasts were washed with PBS and fixed in $100 \%$ ethanol at $37^{\circ} \mathrm{C}$ for 1 hour. Then, fixed cells were washed and serially rehydrated from alcohol series ( 90 to $50 \%$ ) to $\mathrm{H}_{2} \mathrm{O}$. The water was removed and cells were incubated with $5 \% \mathrm{AgNO}_{3}$ at $37{ }^{\circ} \mathrm{C}$ for 15 minute. Subsequently, cells were exposed to fluorescent light and photographed.

Statistical analysis: The values for cell index and mRNA expressions were analyzed by ANOVA using Graph PadPrism software. The results were presented as means \pm SEM. P values $\leq 0.05$ were considered as statistically significant.

"Life Sciences/GIBCO, Paisley, UK

IIII Sigma, St. Louis, MO, USA

$\triangle$ BD Biosciences, Bedford, MA, USA

$\Sigma_{\mathrm{X}}$ CELLigence, ACEA Biosciences, Inc, CA, USA

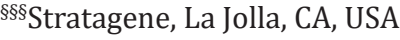

${ }^{\Psi}$ Applied Biosystems, Carlsbad, CA, USA

${ }^{\Phi}$ NanoDrop, Wilmington, DE, USA,

†InVitrogen, Camarillo, CA, USA

${ }^{\ddagger}$ Roche Diagnostics GmbH, Germany

*Insert, Millicell, Millipore, Billerica, MA, USA

${ }^{\dagger+}$ Zeiss EVO ${ }^{\circledR}$ LS 10, Brock \& Michelsen, Denmark

${ }^{+\dagger+T h e r m o ~ F i s h e r ~ S c i e n t i f i c, ~ R e v e r t A i d ~ F i r s t ~ S t r a n d ~ c D N A ~ S y n-~}$ thesis Kit Waltham, MA USA

执Thermo Fisher Scientific' Fermentas Maxima SYBR Green qPCR Master Mix (2X), Waltham, MA USA

\section{Results}

\section{Proliferation}

Until $60 \mathrm{hrs}$, the proliferation trend was similar. According to the statistical analysis, from $70 \mathrm{hrs}$ to the end of the proliferation experiment, reduced cell proliferation was observed in sepiolite group (Figure 1).

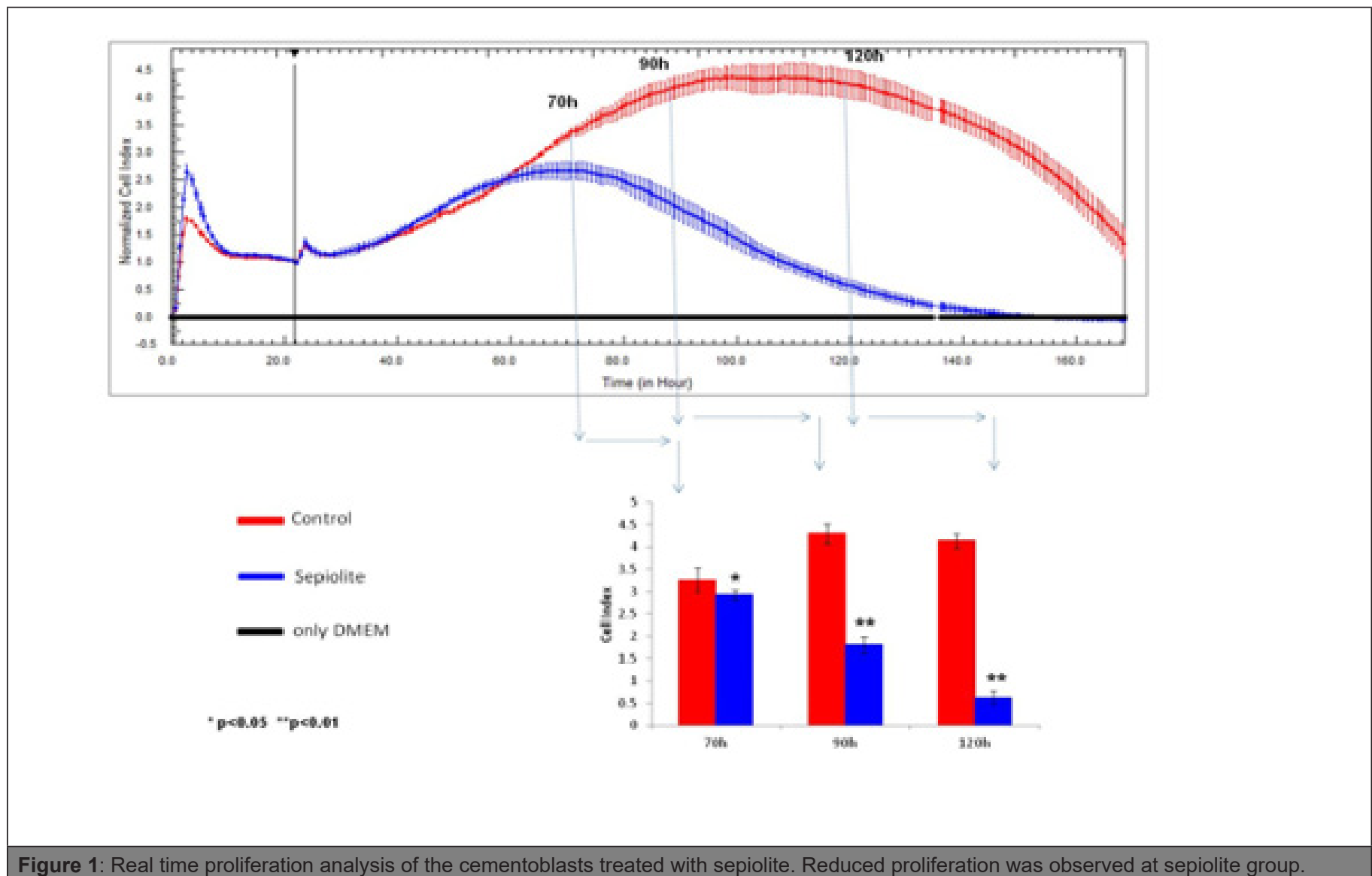

\section{mRNA expression}

Sepiolite induced OCN, COL-I, osteoblastic transcription factor Runx2, and ALP mRNA expression on day 3 and 6 of the cemento- blasts. BSP mRNA expression was not affected when the cells exposed to DMEM containing sepiolite released components (Figure 2). 

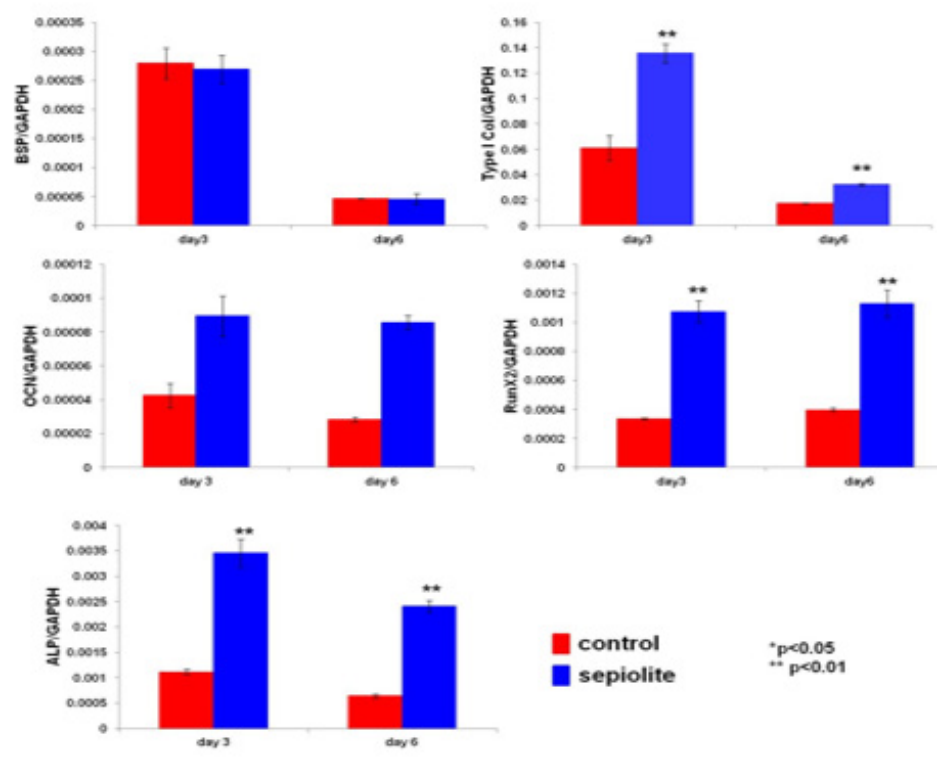

Figure 2: mRNA expressions of mineralized tissue associated genes of cementoblasts on days 3 and 6 . Increased osteocalcin (OCN), collagen type I (COL-I), runt-related transcription factor 2 (Runx2), and alkaline phosphatase (ALP) mRNA expressions were noted in DMEM containg sepiolite released components. BSP mRNA expression was not changed with the sepiolite containing media application.

\section{Mineralization}

Mineralization media treated positive control group had apparent mineral-like nodules when compared to negative control.
DMEM containing sepiolite material induced mineral-like nodules when compared to positive control group (Figure 3).

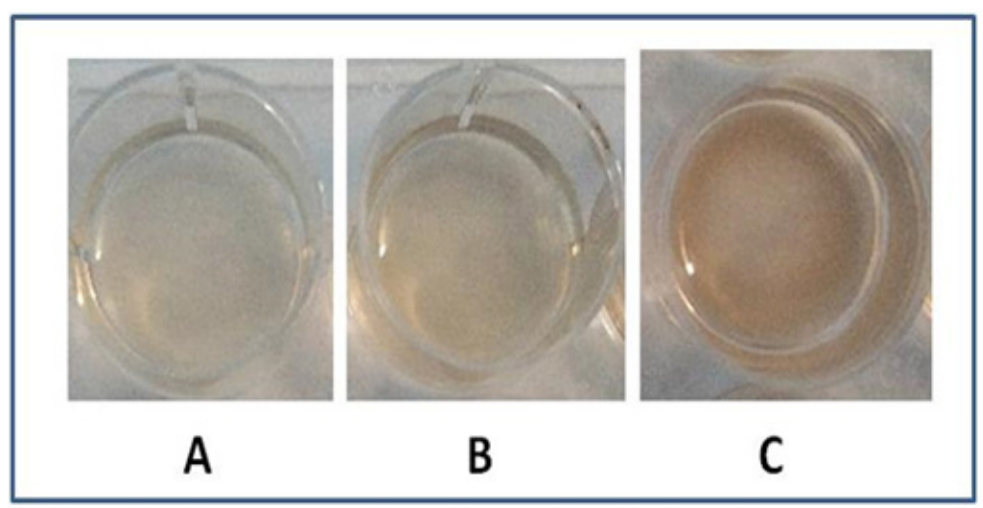

Figure 3: von Kossa staining of the mineralized nodules of the cementoblasts. A: Negative control; without mineralization media, B: Positive control; with mineralization media, C: Sepiolite+mineralization media.

\section{Discussion}

Sepiolite up-regulated significantly important mineralized tissue associated gene's mRNA expressions and biomineralization of the cementoblasts whist it reduced cell proliferation. While the differentiation of the cells was stimulated, reduced proliferation was expected. Cells stop the proliferation, while they synthesized extracellular matrix which was required for differentiation [18].We may conclude that Sepiolite is a promising graft material when the inductive properties taken into account in biomineralization process of the cementoblasts. In our previous study [19], we evaluated different regenerative graft materials (Nanobone $\AA$, BioOss $\AA$, Em- dogain $($, Endobon $($ ) on the cementoblasts and we found that BioOss apparently regulated better gene expressions playing role in the formation mineralized tissues compared to other graft materials. Sepiolite and BioOss were comparable in both mRNA expression and biomineralization experiment. While BioOss bovine derived particulated bone graft, sepiolite is clay materials and absolutely the cost is low and easily accessible when compared to BioOss [19].

In our previous studies, we evaluated the effects of BMP-7, recombinant amelogenin, bFGF, dexamethasone on the cementoblasts [6-8]. According to our experiences on the cementoblasts, sepiolite might be a good candidate material for periodontal tissue 
engineering in dentistry. Further animal studies should be conducted to evaluate potential of sepiolite in the critical size defects for orthopedic usage. Other differentiation and/or growth factors containing graft materials are very expensive. If the targeted effects were possible with the sepiolite, and the response of the cells was comparable, we should prefer cost effective treatment alternatives considering the biological response of the cells to the materials. However, in this study we evaluated only one cell and the cells were mouse originated. And in vitro studies have some limitations to mimic clinical conditions in human. Further studies are required evaluating osteoblasts, periodontal ligament mesenchymal stem cells as well. Moreover, bioactive properties of sepiolite can be enhanced including some element to these materials like boron. In future boron or selenium containing sepiolite biomaterials can be investigated. Sequential elemental releasing can be also considered for future applications.

\section{Acknowledgements}

This work was performed at Selcuk University, Research Center of Dental Faculty, Konya, Turkey and presented European Biotechnology Congress, April 11-13, 2019 Barcelona, Spain. Authors declare no conflict of interest.

\section{Reference}

1. Evans CH (2013) Advances in regenerative orthopedics. Mayo Clin Proc 88(11): 1323-1339.

2. DiGiovanni CW, Petricek JM (2010) the evolution of rhPDGF-BB in musculoskeletal repair and its role in foot and ankle fusion surgery. Foot Ankle Clin 15(4): 621-640.

3. Teng F, Yu D, Wei L, Su N, Liu Y, et al. (2019) Preclinical application of recombinant human bone morphogenetic protein 2 on bone substitutes for vertical bone augmentation: A systematic review and meta-analysis. J Prosthet Dent 122(4): 355-363.

4. Ding T, Li J, Zhang X, Du L, Li Y, et al. (2020) Super-assembled core/shell fibrous frameworks with dual growth factors for in situ cementumligament-bone complex regeneration. Biomater Sci 8(9): 2459-2471.

5. Hakki SS, Bozkurt B, Hakki EE, Kayis SA, Turac G, et al. (2014) Bone morphogenetic protein $2,-6$, and -7 differently regulate osteogenic differentiation of human periodontal ligament stem cells. J Biomed Mater Res B Appl Biomater 102(1): 119-130.
6. Hakki SS, Nohutcu RM, Hakki EE, Berry JE, Akkaya MS, et al. (2005) Dexamethasone and basic-fibroblast growth factor regulate markers of mineralization in cementoblasts in vitro. J Periodontol 76(9): 15501558.

7. Hakki SS, Foster BL, Nagatomo KJ, Bozkurt SB, Hakki EE, et al. (2010) Bone morphogenetic protein-7 enhances cementoblast function in vitro. J Periodontol 81(11): 1663-1674.

8. Hakki SS, BozkurtSB, Türkay E, Dard M, Purali N, etal. (2018) Recombinant amelogenin regulates the bioactivity of mouse cementoblasts in vitro. Int J Oral Sci 10(2): 15.

9. Hakki SS, Bozkurt BS, Hakki EE (2010) Boron regulates mineralized tissue-associated proteins in osteoblasts (MC3T3-E1). J Trace Elem Med Biol 24(4): 243-250.

10. Gümüșderelioğlu M, Tunçay EÖ, Kaynak G, Demirtaș TT, Aydın ST, et al. (2015) Encapsulated boron as an osteoinductive agent for bone scaffolds. J Trace Elem Med Biol 31: 120-128.

11. Karahaliloglu Z, Kilicay E (2020) In vitro evaluation of bone cements impregnated with selenium nanoparticles stabilized by phosphatidylcholine (PC) for application in bone. J Biomater Appl.

12. Demirel M, Aksakal B (2018) Effect of porosity on the structure, mechanical properties and cell viability of new bioceramics as potential bone graft substitutes. Acta Bioeng Biomech 20(2): 11-22.

13. Lauritano D, Limongelli L, Moreo G, Favia G, Carinci F, et al. (2020) Nanomaterials for Periodontal Tissue Engineering: Chitosan-Based Scaffolds. A Systematic Review. Nanomaterials (Basel) 10(4): 605.

14. Handbook of Mineralogy

15. https://www.ima-europe.eu/about-industrial-minerals/industrialminerals-ima-europe/sepiolite

16. Saygin NE, Giannobile WV, Somerman MJ (2000) Molecular and cell biology of cementum. Periodontol 24: 73-98.

17. Foster BL, Popowics TE, Fong HK, Somerman MJ (2007) Advances in defining regulators of cementum development and periodontal regeneration. Curr Top Dev Biol 78: 47-126.

18. Korkusuz P, Hakki SS, Purali N, et al. (2008) Interaction of MC3T3-E1 cells with titanium implants. Joint Dis Rel Surg 19(2): 84-90

19. Mutafcilar E, Bozkurt SB, Götz W, Hakki SS. The effects of different regenerative materials on the tooth root lining cells; cementoblasts. Manuscript in preparation. Unpublished data. 